\title{
Epidemiology and injury severity of 294 extremity gunshot wounds in ten months: a report from the Cape Town trauma registry
}

\author{
Engelmann EWM ${ }^{1} \mathbb{0}$, Maqungo $\mathrm{S}^{2}$, Laubscher $\mathrm{M}^{3} \mathbb{\oplus}$, Hoppe $\mathrm{S}^{4}$, Roche $\mathrm{S}^{5}$, Nicol $\mathrm{A}^{6}$, \\ Navsaria $\mathrm{P}^{7} \mathbb{0}$, Held $\mathrm{M}^{8}$
}

MD, MSc, LLM; Department of Orthopaedic Surgery, Groote Schuur Hospital, University of Cape Town, South Africa

2 MD, FC Ortho; Associate Professor, Department of Orthopaedic Surgery, Groote Schuur Hospital, University of Cape Town, South Africa

3 MBChB, Dip PEC, FC Orth (SA), MMed Ortho (UCT); Department of Orthopaedic Surgery, Groote Schuur Hospital, University of Cape Town, South Africa

4 MD, PhD; Department of Orthopaedic Surgery, Groote Schuur Hospital, University of Cape Town, South Africa; and Department of Orthopaedic Surgery, Division of Spine Surgery, Inselspital Bern, Switzerland

5 MBChB, FCS Orth (SA); Associate Professor, Department of Orthopaedic Surgery, Groote Schuur Hospital, University of Cape Town, South Africa

6 MD; Professor, Department of Traumatology, Groote Schuur Hospital, University of Cape Town, South Africa

MBChB, MMed, FCS, FACS, Trauma Surgery; Professor, Department of Traumatology, Groote Schuur Hospital, University of Cape Town, South Africa

$8 \mathrm{MD}, \mathrm{PhD}$, FC Ortho; Associate Professor, Department of Orthopaedic Surgery, Groote Schuur Hospital, University of Cape Town, South Africa

Corresponding author: Dr EWM Engelmann, 8 James Road, Observatory, 7925, Cape Town, South Africa; email: esmee.engelmann@gmail.com; tel: +31620377825

\section{Abstract}

Aims: To describe the epidemiology and injury severity of patients with extremity gunshot injuries in an area with a high rate of interpersonal violence.

Patients and methods: This is a prospective cohort study of patients who presented with an extremity gunshot injury and were recorded as part of a trauma registry at a large tertiary care hospital in Cape Town, South Africa, between June 2015 and April 2016. Patient demographics, injury severity scores, injury patterns and referral pathways were evaluated.

Results: Of 1123 gunshot trauma admissions in ten months, 290 (25.8\%) patients (91.5\% males, $n=269)$ with a median age of 26 years (IQR 13.0) presented with extremity injuries. Median injury severity score (ISS) was 4.0 (IQR 8.0). Only one-fifth of patients had an ISS of 15 or more $(n=50,17 \%)$. Upper extremity injuries were associated with a higher risk of fractures (RR 2.15 , $p=0.05)$, higher number of nerve injuries $(p=0.01)$, and a two times higher mean ISS $(p=0.01)$. Admissions between $7 \mathrm{pm}$ and 7 am with limited staffing at the emergency department were twice as high as the day admissions $(n=169,57.5 \%$ versus $n=79,26.9 \%)$.

Conclusion: There is a high trauma load on the emergency department and orthopaedic service due to extremity gunshot injuries. Although upper extremity gunshot wounds constituted a red flag for higher injury severity, the overall injury severity was low. Inadequate timing and selection of emergency referrals of patients with low ISS are avoidable aggravators of this burden and should be targeted to increase efficiencies in the care of these patients.

Level of evidence: Level 4

Key words: gunshot, trauma, upper extremity, lower extremity, epidemiology

Citation: Engelmann EWM, Maqungo S, Laubscher M, Hoppe S, Roche S, Nicol A, Navsaria P, Held M. Epidemiology and injury severity of 294 extremity gunshot wounds in ten months: a report from the Cape Town trauma registry. SA Orthop J 2019;18(2):31-36.

http://dx.doi.org/10.17159/2309-8309/2019/v18n2a3

Editor: Dr Franz Birkholtz, Walk-A-Mile Centre for Advanced Orthopaedics, Pretoria, South Africa

Received: June 2018

Accepted: March 2019

Published: May 2019

Copyright: ( 2019 Engelmann EWM, et al. This is an open-access article distributed under the terms of the Creative Commons Attribution Licence, which permits unrestricted use, distribution and reproduction in any medium, provided the original author and source are credited.

Funding: No funding was received for this study.

Conflict of interest: The authors declare they have no conflicts of interest that are directly or indirectly related to the research. 


\section{Introduction}

Armed violence constitutes one of the greatest global health challenges, especially in certain parts of Africa. ${ }^{1-6}$ South Africa's lethal violence rates are close to those of countries at war and Cape Town specifically is one of the most violent cities in the world regarding homicides. ${ }^{4,7}$ In recent years a high rate of interpersonal violence combined with gun trafficking and use of guns as main weapon in gang wars has caused a surge of gun-related injuries (Figure 1). This causes an extreme burden to the health care system in costs as well as hospital stay. ${ }^{7}$

Reports on the epidemiology of civilian gunshot injuries and orthopaedic injury patterns are limited.8,9 Most evidence and guidelines are based on small American and European retrospective case series or military experience with high-velocity injuries. ${ }^{1,3,6,9-11}$ Civilian gunshot trauma is associated with low-velocity injuries in more focal patterns. It is difficult to translate the available literature to civilian gunshot trauma due to distinct injury characteristics and potential of the firearms and bullets. ${ }^{8}$ Moreover, little is known about the trauma burden and injury profile in civilian low-velocity gunshot injuries in low-income countries. Vast differences in injury pattern, associated injuries, system-related resources and the accessibility to health care limit the use of external evidence in the local management of gun-related injuries in these countries.

To date, there are no studies which examine the injury pattern in patients with extremity gunshot injuries in Africa or other lowincome regions. We therefore aimed to describe the demographics, epidemiology and injury pattern of extremity gunshot wounds in a large hospital in Cape Town with the secondary aim to determine factors influencing injury severity.

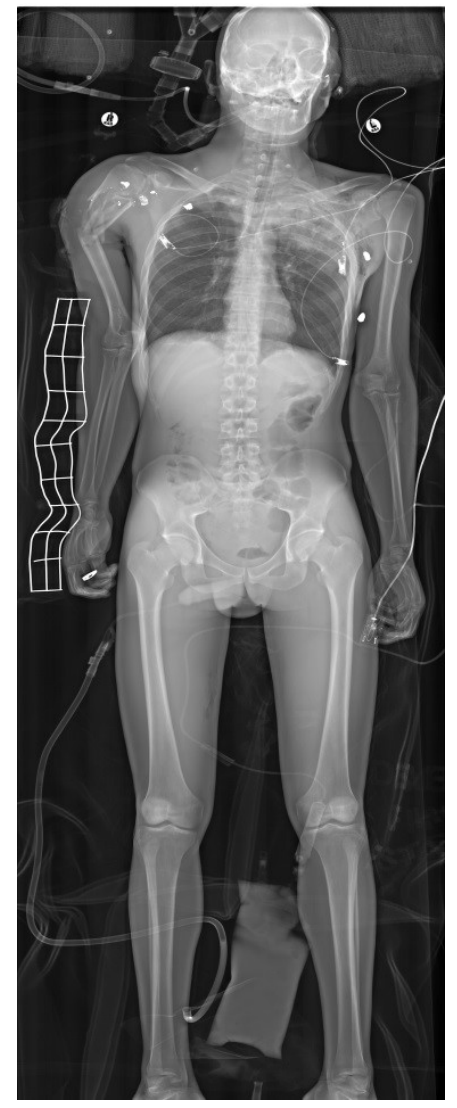

Figure 1. Lodox image (AP view) as part of primary assessment of a patient with multiple upper extremity gunshot injuries at Groote Schuur Hospital Trauma Unit

\section{Methods}

\section{Study design and setting}

The prospectively collected electronic trauma registry of Groote Schuur Hospital, a large tertiary care facility with a Level I Trauma Unit in Cape Town, South Africa was used to extrapolate all patients with gunshot injuries to extremities. ${ }^{12}$ This is an observational study that adheres to the STROBE guidelines for research and was approved by the HREC.

\section{Patients}

All patients with orthopaedic ballistic injuries to the extremities, who presented to the Trauma Unit in a ten-month period from June 2015 to April 2016 were included. Orthopaedic injuries were defined as an acute fracture, dislocation, or fracture dislocation, as well soft tissue, nerve and arterial injuries of the lower and upper extremities. Lower extremity fractures included fractures of the foot, tibia, fibula, patella, femur and acetabulum. Upper extremity fractures were defined as fractures to the hand, ulna, radius, humerus, scapula and clavicle. Patients with incomplete fractures or isolated fractures of the pelvic girdle, spine, skull, face and ribs were excluded. Approval for the prospective collection of data for this registry and the analysis of the collected data was obtained from the Human Research Ethics Council at the University of Cape Town.

\section{Variables, outcome measures, data sources and bias}

Patient demographics, such as age, sex, as well as illicit drug intoxication were recorded. Data on the incident included injury date and time, arrival date and time, type of violence and perpetrator, geolocation, and transport mode to the hospital. Children were defined as patients under 19 years of age. This hospital does not admit children under 13 years of age as these patients are treated at a specific children's hospital. Injuries were classified according to triage code $(1=$ green, standard; 2 = yellow, urgent; 3 = red, very urgent), anatomical site, injury type, Abbreviated Injury Scale (AIS), Injury Severity Score (ISS), Glasgow Coma Scale (GCS) and Revised Trauma Score (RTS). The type of injury was described as fracture, abrasion, contusion, haematoma, or superficial laceration. Associated injuries were defined as injury to an anatomical structure other than the upper and lower extremity.

\section{Statistical analysis, study size}

Demographic and clinical data were compared using bivariate analysis. The p-values were determined by the chi-squared or two-sided Fisher's exact test for categorical variables, and by the Student's $t$ test or the Mann-Whitney $U$ test for continuous variables. Differences in two population proportions or means were calculated using one- or two-tailed $Z$ tests. One-way ANOVA was used to determine differences between the means of two or more independent groups. Risk factors identified by bivariate analysis at $p<0.1$ were put into a logistic regression model to test for association with injury severity. Significant confounders $(p<0.05)$ between the compared groups were identified using multivariate analysis. Univariate and multivariate analyses were performed to investigate associations between demographical characteristics, anatomic site of injury and injury severity. Values are reported as percentages for categorical variables and mean + SD for continuous variables. $P$-values lower than 0.05 were regarded significant. Analyses were

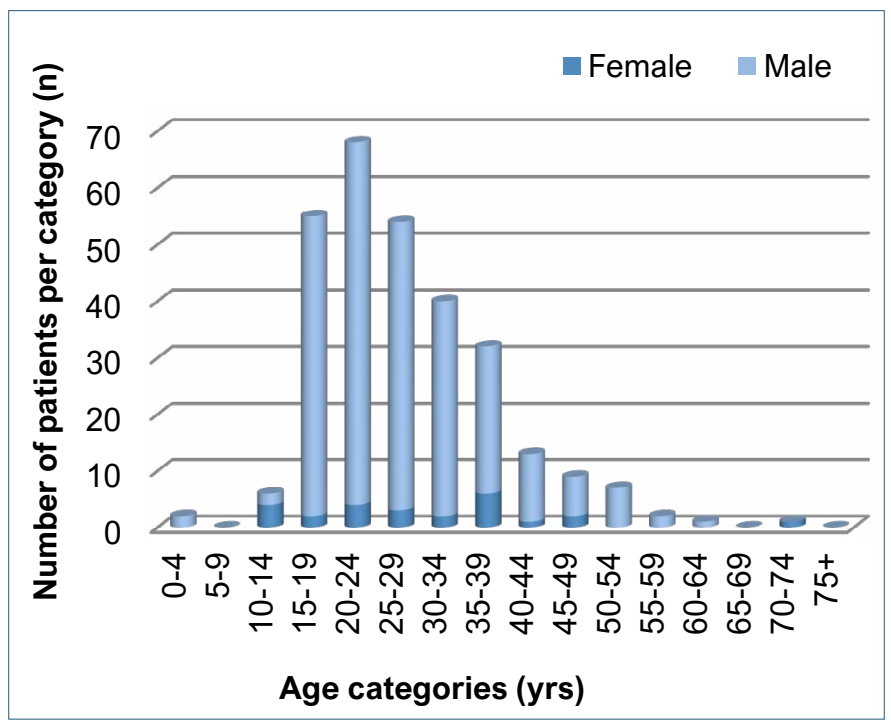

Figure 2. Age-sex distribution of patients $(n=290)$ 
performed using Statistica 13 (DELL Software, California) and SPSS version 23 (Statistical Package for the Social Sciences, IBM Company, New York).

\section{Results}

\section{Demographics and epidemiology}

A total of 294 of 1123 (26.2\%) cases (269 male, 90.1\%) had extremity injuries (Figure 2). Four patients were readmitted for a repeat gunshot injury during the study period (1.4\%) resulting in a total of 294 cases in 290 patients. The demographic data is shown in Table I. There were 243 adults (82.7\%) and 47 children (16.2\%). Of the 230 patients who were tested for intoxications, 32 were positive for alcohol (13.9\%), 39 for illegal drugs (17.0\%), and 18 for both alcohol and illegal drugs (7.8\%). The average age was 28.1 years (median 26.1; IQR=13.0, Figure 2). Most injuries were the result of intentional violence $(n=265 ; 90.1 \%)$. Gang-related violence accounted for $37.1 \%(n=109)$ of injuries. While 181 victims were shot on the streets (61.6\%), 44 were shot at home (15\%). A peak incidence was observed in the summer months from September to January with more than 35 admissions per month compared to 20 admissions per month during the rest of the year. One-third of admissions occurred on weekends ( $n=98 ; 33.3 \%$ ) compared to two-thirds during the five weekdays $(n=196 ; 66.7 \%)$. Most patients were shot on Sunday $(n=59 ; 20.1 \%)$.

Table I: Demographics and admission data

\begin{tabular}{|c|c|}
\hline Variables & Patients (n; \%) \\
\hline Patients (n) & 294 \\
\hline \multicolumn{2}{|l|}{ Age (yrs) } \\
\hline Mean $\pm S D$ & $28.1 \pm 10.1$ \\
\hline Median & 26.1 \\
\hline Range & $0.8-74.7$ \\
\hline \multicolumn{2}{|l|}{ Sex } \\
\hline Male & 269 (91.5\%) \\
\hline Female & $25(8.5 \%)$ \\
\hline \multicolumn{2}{|l|}{ Type of conflict } \\
\hline Intentional & $265(90.1 \%)$ \\
\hline Non-intentional & $29(9.9 \%)$ \\
\hline \multicolumn{2}{|l|}{ Perpetrator } \\
\hline Stranger & $124(42.2 \%)$ \\
\hline Family/friends/acquaintance & $25(8.5 \%)$ \\
\hline Police/legal intervention & $4(1.4 \%)$ \\
\hline Unknown & $141(48.0 \%)$ \\
\hline \multicolumn{2}{|l|}{ Transport } \\
\hline Ambulance & $256(87.1 \%)$ \\
\hline Vehicle & $18(6.1 \%)$ \\
\hline Walked & $3(1.0 \%)$ \\
\hline Unknown & $17(5.8 \%)$ \\
\hline \multicolumn{2}{|l|}{ Transfer } \\
\hline Direct from scene & $108(36.7 \%)$ \\
\hline Inter-facility transfer & $137(46.6 \%)$ \\
\hline Unknown & $49(16.7 \%)$ \\
\hline \multicolumn{2}{|l|}{ Time of arrival } \\
\hline 7am-7pm & $79(26.9 \%)$ \\
\hline 7pm-7am & $169(57.5 \%)$ \\
\hline Unknown & $46(15.6 \%)$ \\
\hline \multicolumn{2}{|l|}{ Time injury to admission } \\
\hline 0 to 1 hour & $32(10.9 \%)$ \\
\hline 1 to 2 hours & $52(17.7 \%)$ \\
\hline 2 to 3 hours & $29(9.9 \%)$ \\
\hline More than 3 hours & $72(24.5 \%)$ \\
\hline Unknown & $109(37.1 \%)$ \\
\hline
\end{tabular}

Table II: Clinical details

\begin{tabular}{|c|c|}
\hline Variables & Patients (n; \%) \\
\hline Patients (n) & 294 \\
\hline Triage & \\
\hline 1 & $107(35.4 \%)$ \\
\hline 2 & $149(50.7 \%)$ \\
\hline 3 & $38(12.9 \%)$ \\
\hline ISS & \\
\hline Mean $\pm S D$ & $7.7 \pm 9.4$ \\
\hline Median & 4 \\
\hline Range & $0-75$ \\
\hline$>15$ & $50(17.0 \%)$ \\
\hline Orthopaedic injuries & \\
\hline Upper extremity & $90(30.6 \%)$ \\
\hline Lower extremity & $186(63.3 \%)$ \\
\hline Both & $18(6.1 \%)$ \\
\hline Other injuries & \\
\hline Abdomen & $49(16.7 \%)$ \\
\hline Chest & $26(8.8 \%)$ \\
\hline Head/neck & $10(3.4 \%)$ \\
\hline Urogenital & $13(4.4 \%)$ \\
\hline
\end{tabular}

Table III: Anatomical distribution of fractures

\begin{tabular}{|c|c|}
\hline Bone & Fractures $n=70$ \\
\hline $\begin{array}{l}\text { Tibia/fibula } \\
\text { Femur } \\
\text { Foot } \\
\text { Acetabulum } \\
\text { Patella }\end{array}$ & $\begin{array}{c}28(42.4 \%) \\
27(38.6 \%) \\
11(15.7 \%) \\
2(2.9 \%) \\
2(2.9 \%)\end{array}$ \\
\hline Bone & Fractures $n=72$ \\
\hline $\begin{array}{l}\text { Radius/ulna } \\
\text { Humerus } \\
\text { Clavicle } \\
\text { Scapula } \\
\text { Hand }\end{array}$ & $\begin{array}{c}26(39.3 \%) \\
18(27.2 \%) \\
4(6.1 \%) \\
9(13.6 \%) \\
19(28.8 \%)\end{array}$ \\
\hline
\end{tabular}

Table IV: Clinical characteristics of major trauma patients

\begin{tabular}{lc} 
& ISS>15 (n=50) \\
\hline Intentional & $90 \%(45)$ \\
Gang-related & $34 \%(17)$ \\
$7 p m-7 a m$ & $68 \%(34)$ \\
Intoxication & $38 \%(19)$ \\
Multiple GSW & $90 \%(45)$ \\
Fractures & $66 \%(33)$ \\
Neurovascular injuries & $10 \%(5)$
\end{tabular}

\section{Factors affecting injury severity}

The mean ISS was $7.7+9.4$ with a median of 4 ranging from 0 to $75(\mathrm{IQR}=8.0)$. Fifty patients (17\%) had an ISS of $>15$, suggestive of major trauma. ${ }^{13}$ The average RTS was $6.9+0.3$ ranging from 4 to 7. Detailed clinical characteristics are presented in Table II and III. Further pre-hospital characteristics of this severely injured group are displayed in Table IV. In analysis of time to admission and mean ISS, patients admitted two hours or more after injury were found to have a significantly lower mean ISS $(p=0.03)$ (Figure 3). Compared to the lower limb, upper extremity gunshot wounds increased the risk of a fracture 2.15 times $(95 \% \mathrm{Cl}$ 1.07-3.07; $p=0.02$ ); had a higher number of nerve injuries; a greater risk of associated abdominal or thoracic injuries with a risk ratio of 2.42 (95\% Cl 1.74-3.37); a higher number of triage code red patients $(p=0.002)$; a higher mean ISS $(p=0.008 ; t=-2.679 ; 95 \%$ $\mathrm{Cl}-5.55$ to -0.85$)$; and greater number of patients with an ISS $>15$ $(p=0.03)$ (Table $V)$. Arterial injuries were reported more frequently in the lower extremity group $(p=0.1)$. 


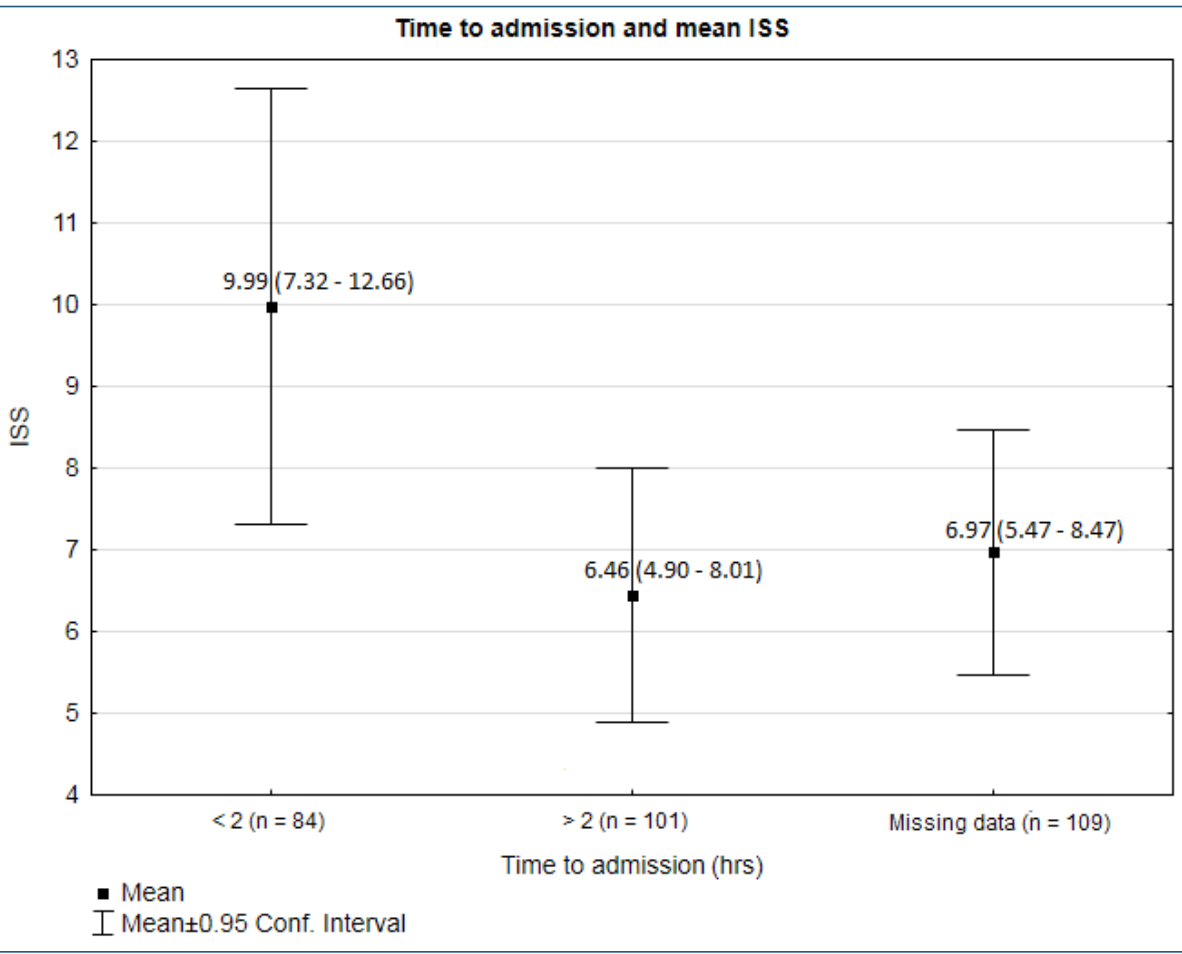

Figure 3. Box-plot of mean ISS and 95\% confidence interval against time to admission

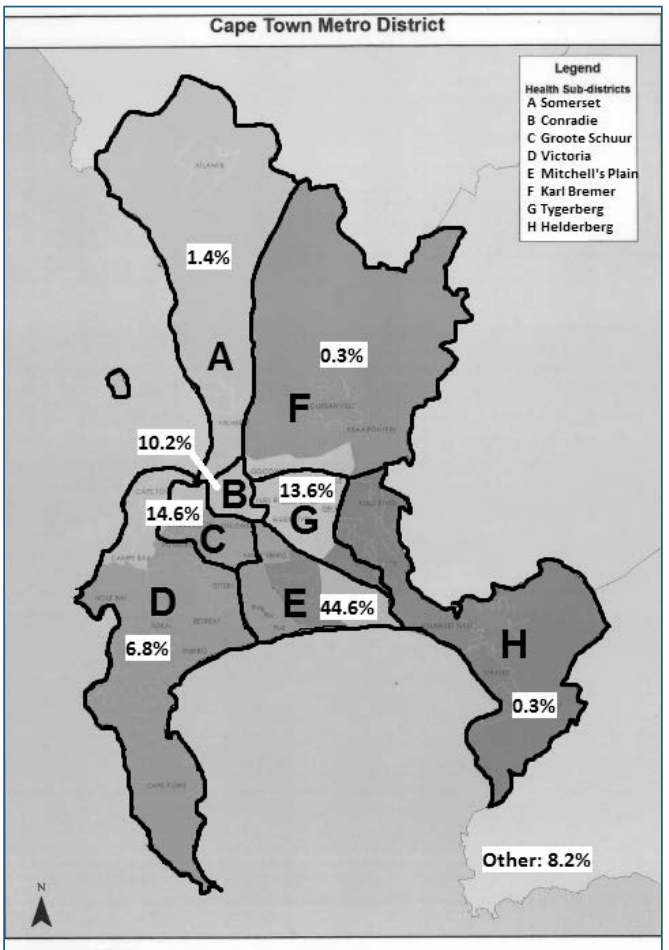

Figure 4. Geographic distribution of admissions
Table V: Comparison of injuries in the upper and lower extremity

\begin{tabular}{|c|c|c|c|}
\hline & $\begin{array}{l}\text { Upper } \\
\text { extremity }\end{array}$ & $\begin{array}{l}\text { Lower } \\
\text { extremity }\end{array}$ & Both \\
\hline $\begin{array}{l}\text { Patients }(n) \\
\text { Triage }\end{array}$ & 90 & 186 & 18 \\
\hline 1 & 42 (46.7\%) & $51(27.4 \%)$ & $14(77.8 \%)$ \\
\hline 2 & 30 (33.3\%) & 115 (61.8\%) & $4(22.2 \%)$ \\
\hline $\begin{array}{l}3 \\
\text { ISS }\end{array}$ & 18 (20.0\%) & 20 (10.8\%) & $0(0 \%)$ \\
\hline Mean \pm SD & $9.4 \pm 9.9$ & $6.2 \pm 9.0$ & $14.1 \pm 7.7$ \\
\hline Median & 9 & 4 & 13 \\
\hline Range & $0-59$ & $0-75$ & $1-29$ \\
\hline $\begin{array}{l}>15 \\
\text { Fractures }\end{array}$ & 21 (23.3\%) & 24 (12.9\%) & 5 (27.8\%) \\
\hline None & 40 (44.4\%) & $138(74.2 \%)$ & $5(27.8 \%)$ \\
\hline One & $36(40.0 \%)$ & $35(18.8 \%)$ & 6 (33.3\%) \\
\hline Two & $12(13.2 \%)$ & $10(5.4 \%)$ & $4(22.2 \%)$ \\
\hline $\begin{array}{l}\text { Three and more } \\
\text { Associated } \\
\text { injuries }\end{array}$ & $2(2.2 \%)$ & $3(1.6 \%)$ & $3(16.7 \%)$ \\
\hline Nerve & 9 (10.0\%) & $3(1.6 \%)$ & $0(0 \%)$ \\
\hline Arterial & 6 (6.7\%) & 24 (12.9\%) & 2 (11.1\%) \\
\hline Other injuries & & & \\
\hline Abdomen & 23 (25.6\%) & 20 (10.8\%) & 6 (33.3\%) \\
\hline Chest & 17 (18.9\%) & $6(3.2 \%)$ & $3(16.7 \%)$ \\
\hline Head/neck & $6(6.7 \%)$ & $4(2.2 \%)$ & $0(0 \%)$ \\
\hline Urogenital & $2(2.2 \%)$ & $11(5.9 \%)$ & $1(5.6 \%)$ \\
\hline
\end{tabular}

\section{Referral patterns}

Most patients were brought in by ambulance $(n=256 ; 87.1 \%)$. Onethird $(n=108 ; 36.7 \%)$ presented directly from the scene; almost half of the patients $(n=137,46.6 \%)$ had an interfacility transfer prior to admission to our hospital. In 49 patients (16.7\%) no transfer data was available. Most patients were transferred within two hours of injury. Injury severity did not have a significant influence on transport and transfer. A map of Cape Town and its surrounding areas is provided in Figure 4, depicting the assigned referral areas for regional public hospitals. Only 43 patients (14.6\%) came from the specific referral area (Figure 4, area C) of the facility. Most patients were injured in the townships (area E) and informal settlements in the Cape Flats $(n=131,44.6 \%)$. Compared to other areas, fewer patients in these townships came directly from the scene $(n=37 ; 28.2 \%)$ as most patients had an inter-facility transfer. Admissions between $7 \mathrm{pm}$ and 7 am were twice as high as the day admissions $(n=169,57.5 \%$ and $n=79,26.9 \%$, respectively).

\section{Discussion}

This study shows a very high burden of extremity gunshot injuries to the emergency and orthopaedic trauma service of a large tertiary care facility in Cape Town. This was aggravated by inadequate emergency referrals of patients, regarding low ISS, timing of the transfer at night time, and referrals from areas outside the referral area. Although the lower extremity was shot more frequently, upper extremity gunshot injuries are associated with a higher rate of fractures, nerve injuries, and ISS and constitute a red flag. Alarming was the high rate of children (16\%) among the victims.

Most patients were young males intentionally shot by strangers. The age and sex distribution were similar to those in the literature, with a lower median age of patients involved in gang violence. . $^{1,311,14}$ The high rate of alcohol or drug abuse of those tested was consistent with other studies. ${ }^{15,16}$ Most injuries occurred on the streets in the Cape Flats township area, known for a high rate of gang-related violence. ${ }^{17,18}$ We also noticed a high rate of underage victims in Cape Town, which shows the effect of armed violence on an extremely vulnerable group. ${ }^{19,20}$

Most patients were admitted to our hospital after an inter-hospital transfer, although 83\% were not severely injured (ISS lower than $15)$ and were inadequate referrals for tertiary emergency care. Trauma overload at local township hospitals, resource restrictions or an initial overestimation of injury severity might be reasons for this. Only $20 \%$ of the patients came from the actual drainage area (Figure 4). ${ }^{21}$ Access to our tertiary care hospital for these patients was acceptable with an average delay from injury to admission of two hours. The time to admission was shorter in patients with a higher ISS compared to patients with a lower ISS, suggesting that 
the pre-hospital triage and referral system adequately prioritises more severely injured patients. Most of the patients with low ISS were brought to the emergency department during the night, which poses an additional burden on the trauma services often with minimal staffing during this time. A similar finding was reported previously in another area of high gang violence. ${ }^{11}$ This shows the need for support in the decision-making for referrals of extremity gunshot injuries to tertiary care emergency facilities in our area which should be reserved for patients who require specialised clinical resources and expertise. ${ }^{22}$ A better understanding of factors influencing injury severity could help to guide this process.

Patients with upper extremity injuries had a higher median ISS and a higher risk of associated and other injuries compared to patients with lower extremity injuries; this is most likely due to the proximity to the head, as well as thoracic and abdominal vital organs. Lichte et al. described high rates of mortality in civialin gunshot injuries to the torso. ${ }^{8}$ However, the injury profile of orthopaedic injuries has not been studied before. Based on our novel findings, upper extremity injuries should therefore be regarded as a red flag in the primary survey of orthopaedic ballistic trauma patients.

A limitation to this study is that the trauma registry is maintained by treating clinicians, and the high trauma burden might have led to a lower quality of data collection. However, previous assessment of this clinician-driven data collection proved to be feasible and this is the first registry of its kind in Africa and provides important insight on patient demographics, injuries, and the local trauma health care system. ${ }^{12}$ Another limitation was that data assessing the burden of gunshot-related injuries in our referring hospitals was not included in this study, which might have provided better insight into the patient flow into our hospital. Currently there are no databases available in the township hospitals. We also did not classify the fractures according to their severity which might have triggered referral to our tertiary care orthopaedic service. Yet, most patients with low injury severity should have been referred to orthopaedic clinics without overloading the emergency intake of our trauma unit.

\section{Conclusions}

This is the first large prospective registry-based study on the epidemiology, injury severity and admission data of civilian gunshot injuries in a low-income setting. Our findings are key to better understanding the effects of the extremely high burden of gunshot injuries in (South) Africa and to find possible indigenous solutions.

Although most gunshot injuries to the extremities were not lifethreatening, upper extremity gunshot wounds constituted a red flag for higher injury severity. Inadequate timing and selection of emergency referrals of patients with low ISS are avoidable aggravators of this burden and should be targeted to increase efficiency in the care of these patients. Suggestions for clinical practice include the need for more physicians and other staff at night, as well as increased awareness regarding the involvement of underaged patients. Future research should assess criteria for referral, admission and surgical intervention for these injuries and evaluate treatment algorithms with least burden on the health care system and best possible outcomes with available resources. ${ }^{22}$

\section{Ethics statement}

All procedures performed in studies involving human participants were in accordance with the ethical standards of the institutional and/or national research committee and with the 1964 Helsinki declaration and its later amendments or comparable ethical standards. Given the observational character and retrospective analysis, formal consent was not required for this study.

\section{Declaration}

The authors declare authorship of this article and that they have followed sound scientific research practice. This research is original and does not transgress plagiarism policies.

\section{Acknowledgements}

We thank Dr Richard Spence for his support in management of the eTHR database.

\section{Author contributions}

EE conducted the study, data analysis and wrote the manuscript. SM, ML and SR managed the patients and contributed to the final write-up of the manuscript. AN and $\mathrm{PD}$ contributed to the data collection, managed the database, and contributed to the final manuscript. SH assisted with the protocol and data analysis, and contributed to the protocol and final manuscript. MH supervised the study, contributed to the original study concept, data analysis and manuscript of the study.

\section{ORCID}

EWM Engelmann (iD) http://orcid.org/0000-0002-7685-4024

M Laubscher iD http://orcid.org/0000-0002-5989-8383

P Navsaria (iD http://orcid.org/0000-0002-5152-3317

M Held (iD http://orcid.org/0000-0002-0671-0439

\section{References}

1. Brown TD, Michas P, Williams RE, Dawson G, Whitecloud TS, Barrack RL. The impact of gunshot wounds on an orthopaedic surgical service in an urban trauma center. Journal of Orthopaedic Trauma. 1997;11(3):149-53.

2. Geneva Declaration Secretariat. Global Burden of Armed Violence 2015. Geneva, 2015.

3. Persad IJ, Reddy RS, Saunders MA, Patel J. Gunshot injuries to the extremities: experience of a UK trauma centre. Injury. 2005;36(3):407-11.

4. United Nations Office on Drugs and Crime. Global Study on Homicide. Homicide Statistics 2013; Homicide Counts and Rates, Time Series 2000-2012. 2013.

5. United Nations General Assembly. Report of the Panel of Governmental Experts on Small Arms. General and Complete Disarmament: Small Arms. New York, 1997.

6. Volgas DA, Stannard JP, Alonso JE. Current orthopedic treatment of ballistic injuries. Injury. 2005;36(3):380-86.

7. Martin C, Thiart G, McCollum G, Roche S, Maqungo S. The burden of gunshot injuries on orthopaedic healthcare resources in South Africa. S Afr Med Journal, 2017;107(7):626-30.

8. Lichte P, Oberbeck R, Binnebosel M, Wildenauer R, Pape HC, Kobbe P. A civilian perspective on ballistic trauma and gunshot injuries. Scand J Trauma Resusc Emerg Med, 2010;18(35).

9. Held M, Engelmann E, Dunn R, Ahmad S, Laubscher M, Keel M. Gunshot induced injuries in orthopaedic trauma research. A bibliometric analysis of the most influential literature. Orthopaedics \& Traumatology: Surgery \& Research. 2017;103(5):801-807.

10. Gunst M, Ghaemmaghami V, Gruszecki A, Urban J, Frankel $H$, Shafi S. Changing epidemiology of trauma deaths lead to a bimodal distribution. Proceedings (Baylor University Medical Center). 2010;23(4):349-54.

11. Song DH, Naude GP, Gilmore DA, Bongard F. Gang warfare: the medical repercussions. Journal of Trauma - Injury Infection and Critical Care. 1996;40(5):810-15.

12. Zargaran E, Schuurman N, Nicol AJ, Matzopoulos R, Cinnamon J, Taula T, Ricker B, Ross Garbutt Brown D, Navsaria P, Morad Hameed S. The electronic trauma health record: design and usability of a novel tablet-based tool for trauma care and injury evaluation of 294 patients at a level I trauma centre in South Africa 17 surveillance in low resource settings. Journal of the American College of Surgeons. 2014;218(1):41-50.

13. Butcher N, Balogh Z. Update on the definition of polytrauma. European Journal of Trauma and Emergency Surgery. 2014;40(2):107-11.

14. Woloszyn JT, Uitvlugt GM, Castle ME. Management of civilian gunshot fractures of the extremities. Clinical Orthopaedics and Related Research. 1988;226:247-51. 
15. Black M, Ricardo I. Drug use, drug trafficking, and weapon carrying among low-income, African-American, early adolescent boys. Paediatrics. 1994;72:1065.

16. Cherpitel C. Alcohol and casualties: a comparison of emergency room and coroner data. Alcohol and alcoholism. 1994;29:211.

17. Jensen S. Gangs, politics and dignity in Cape Town. The University of Chicago Press Books; 2008.

18. Petrus T. Enemies of the 'state': vigilantism and the street gang as symbols of resistance in South Africa. Aggressive Violent Behavior. 2015;22:26-32.

19. Campbell N, Colville J, van der Heyde Y, van As A. Firearm injuries to children in Cape Town, South Africa: impact of the 2004 Firearms Control Act. S Afr J Surg 2014;51(3):92-96.

20. Wesson $H$, Bachani A, Mtambeka P, Schulman D, Mavengere $C$, Ward Millar A, Hyder A, van AS A. Changing state of pediatric injuries in South Africa: An analysis of surveillance data from a Pediatric Emergency Department from 2007-2011. Surgery 2017;162(6S):S4-S11.

21. Government Western Cape. Map of referral and support areas for public hospitals in the Western Cape. Cape Town, 2015.

22. Meara JG, Leather AJM, Hagander L, Alkire BC, Alonso N, Ameh EA, Bickler SW, Conteh L, Dare AJ. Global surgery 2030: evidence and solutions for achieving health, welfare and economic development. The Lancet. 2015;386(9993):569-624. 